\title{
Detection of Citations by Log Information to Prevent Reference Omissions
}

\author{
Hiroyuki Makabe, Chikako Ishizawa ${ }^{*}$, Yoichi Kageyama \\ Akita University, 1-1 Tegata Gakuen-machi, Akita-shi, Akita 010-8502, Japan \\ *Corresponding Author: ishizawa@ie.akita-u.ac.jp
}

\begin{abstract}
It is necessary to include bibliographic references in books, documents, newspaper articles, among others, which are ideally referred to during the creation of reports or articles. However, as the description of the references (bibliographic references) is left to the user's discretion, their omission due to the user's carelessness is a problem. To prevent this form of reference omission, a method exists that can detect sentences created by copying them from other electronic documents. This would give the user the references that need to be mentioned at the end of their article. In this paper, we will improve upon the previous method of detection accuracy for sentences created using the copy and paste operation and the process of displaying them to the user for easy understanding. Additionally, we will examine the detected sentences that are required to describe the reference that was generated without using the copy and paste operation.
\end{abstract}

Keywords: PC operation logs, reference, human error, user assist

\section{Introduction}

With the spread of the Internet, unauthorized use of copyrighted works is on a rise. Sentences and images are protected by copyright, and when using a work, it is necessary to describe the citation. However, to describe the reference is left to the user's judgment, and the omission of the reference due to the user's mistake is a problem ${ }^{(1,2)}$.

A product that can manage reference information is Copypelna (ANK Co. Ltd.) ${ }^{(3)}$. It uses a function that presents the user with a web page or file that has identical or similar sentences. Specifically, based on the words in the document created by the user, a search is conducted on texts or proprietary databases available on the Internet. This product is used to check completed documents as it can identify possible plagiarism.

On the contrary, the unauthorized use of a sentence is sometimes caused due to a human error such as careless omission of the reference. Therefore, we consider it necessary to have a system that can check whether the reference has been included or not and, in turn, provide the user with the reference, if there is an omission. The purpose of this research is to develop a method to organize and present information about sentences created based on citations to prevent the omission of references that occur when creating documents using a computer.

We analyzed the already existing proposed method to detect sentences created by paraphrasing the copied sentences from other electronic documents (referred to as conventional method) ${ }^{(4)}$. We laid focus on the copy and paste operations and the similarity between character strings. The results clarified that the sentences created using the following two ways could be detected:

(a) The inserted text is not changed (citation is mentioned).

(b) The inserted text is changed, summarized, etc. (reference sentence is provided).

However, the following issues are still present using the existing method:

(1) It is difficult to detect a sentence created by copying only a part of the sentence such as a word or phrase.

(2) It is difficult to understand the correspondence between the detected sentence (the sentence that needs to have reference) and the displayed bibliographic information.

(3) The sentence cannot be detected if the sentence is cited without performing the copy operation.

Therefore, in this paper, we will improve upon the 
conventional method to solve the above-mentioned problems (1) and (2). Additionally, we will examine the case to read a document and make sentences without using copy and paste operation to solve problem (3).

\section{Improvement of the Method to Detect Sentences Created by Copy Operation}

\subsection{Outline of the Proposed Method}

An outline of our proposed method is shown in Fig. 1. The proposed method comprises "Process to obtain logs," "Process to detect reference sentence and citation sentence," and "Process to display results." The flow of each process is the same as that of the conventional method.

In the log obtain processing, texts in the clipboard of the PC, URL, etc. are recorded in the log when the copy and paste operations are performed during the document creation.

The process of detecting reference sentence and citation sentence is to identify a sentence created by the copy and paste operation in a document file as a sentence that needs to be described in the reference. To enhance the detection accuracy of sentences created using the copy and paste operation, we will improve upon the detect processing feature in Section 2.2.

While displaying results, detected sentences are displayed through color coding. In the conventional method, although the results are classified as "citation sentence" and "reference sentence," the user's judgment still remains difficult. Therefore, we will improve this display processing feature in Section 2.3.

\subsection{Process to Detect Reference Sentence and Citation Sentence}

Fig. 2 shows the flow of the process after improvement. First, the work file and log file are read. Next, the URL detection process is executed. Finally, the process to detect text created by reference sentence (usage (b) in Chapter 1) and the process to detect text created by citation sentence (usage (a) in Chapter 1) are sequentially executed. In the proposed method, to enable detection of sentences created by partial copying, the order of processing has been changed so that "detect text created by citation sentence" is performed after "detect text created by reference sentence."

\subsection{Process to Display Results}

In the proposed method, improvements are made to a sentence where copy source information is not described in the reference. These sentences are color-coded for each reference document information and presented on the display. Fig. 3 shows an example of the indication window with the detection results. The details of the text shown in the Fig. 3 are shown in Table 1 for the left sentence and in Table 2 for the right sentence.

The left side is used for displaying sentences read from working file and the right side is used as an area for displaying copy source information, that is, information necessary for the reference.

On the left side, the sentences, words, and phrases

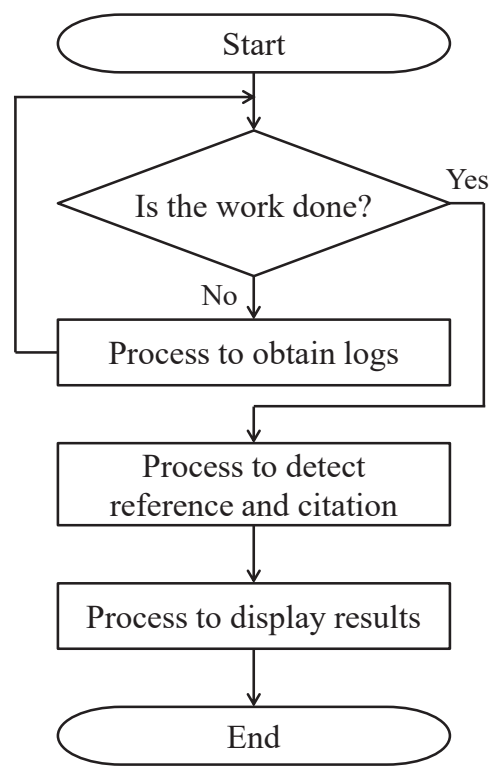

Fig. 1. Outline of our proposed method.

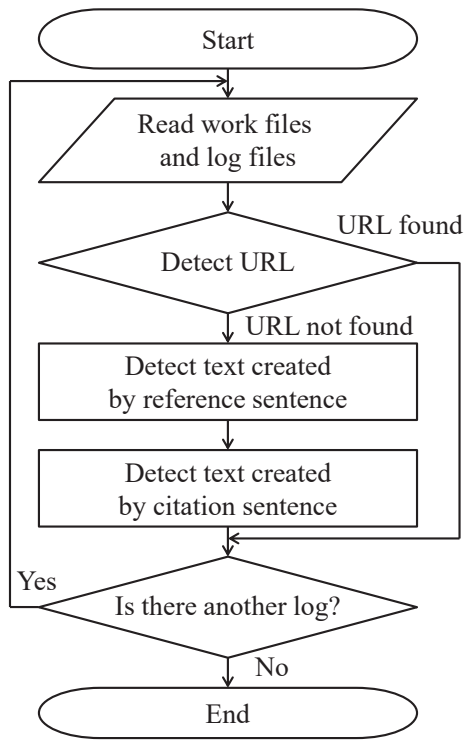

Fig. 2. Flowchart of process to detect reference sentence and citation sentence. 
created by the copy and paste operation are colored, whereas the sentences, made without copy and paste operations are not colored. On the right side, we add processing to prevent multiple displays of the same information. The process determines whether the reference information of the sentence detected is the same as the information present in the sentence that has already been detected. In the case of a new reference information, a new color is assigned to the detected sentence and reference information. Furthermore, in the case of existing reference information, the existing color is assigned to the sentence detected. This process makes the correspondence between the sentence created by copy and paste operation and the reference clearer.

\subsection{Comparison with Similar Products}

(a) Experimental conditions

To evaluate the usefulness of the proposed method, experiments are performed using a comparative method. A total of 132 patterns are created by combining the three items (I to III) shown in Table 3. These patterns are manipulated using the proposed method and Copypelna, and the results are examined. If the copy source information is correctly displayed in the place where the copy and paste operation is performed, it is defined as success; otherwise, it is defined as failure. The experimental conditions are as follows:

$\checkmark \quad$ OS: Microsoft ${ }^{\circledR}$ Windows ${ }^{\circledR} 10$ Home 64 bit

$\checkmark \quad$ CPU: Intel ${ }^{\circledR}$ Core $^{\mathrm{TM}}$ i5-3470 CPU @3.20GHz

$\checkmark$ Software: Microsoft ${ }^{\circledR}$ Word $^{\circledR}$

$\checkmark$ Morphological analysis engine: $\mathrm{NMeCab} 0.07^{(5,6)}$

$\checkmark$ Dictionary for morphological analysis: mecab-ipadicNEologd $d^{(7)}$

$\checkmark \quad$ List of stop words: SlothLib ${ }^{(8)}$

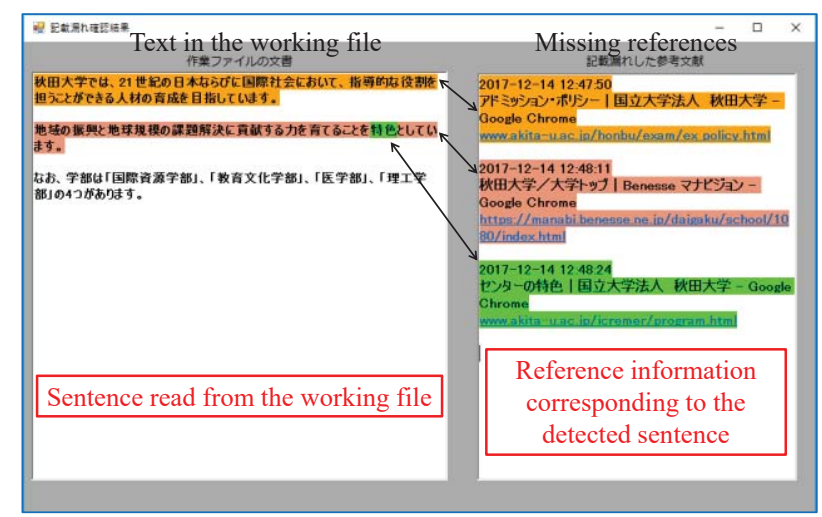

Fig. 3. Indication window with the detection results.
Table 1. Details of the text on the left side of the indication window.

\begin{tabular}{|c|l|}
\hline $\begin{array}{c}\text { Sentence } \\
\text { number }\end{array}$ & \multicolumn{1}{|c|}{ Contents of sentences } \\
\hline \multirow{5}{*}{1} & $\begin{array}{l}\text { 秋田大学では、21 世紀の日本ならびに国 } \\
\text { 際社会において、指導的な役割を担うこと } \\
\text { ができる人材の育成を目指しています。 } \\
\text { Akita University aims to develop human } \\
\text { resources who can play a leading role in 21st } \\
\text { century Japan and the international } \\
\text { community. }\end{array}$ \\
\hline \multirow{5}{*}{3} & $\begin{array}{l}\text { 地域の振興と地球規模の課題解決に貢献 } \\
\text { する力をて育てることを特色としています。 } \\
\text { It is characterized by nurturing the ability to } \\
\text { contribute to regional development and global } \\
\text { problem solving. }\end{array}$ \\
\hline $\begin{array}{l}\text { なお、学部は「国際資源学部」、教育文化 } \\
\text { 学部」、「医学部」、「理工学部」の } 4 \text { つがあ } \\
\text { ります。 } \\
\text { In addition, there are four departments: } \\
\text { “Faculty of International Resource Sciences”, } \\
\text { “Faculty of Education and Human Studies”, } \\
\text { “Faculty of Medicine”, and “Faculty of } \\
\text { Engineering Science”. }\end{array}$ \\
\hline
\end{tabular}

Table 2. Details of the text on the right side of the indication window.

\begin{tabular}{|c|c|}
\hline $\begin{array}{c}\text { Sentence } \\
\text { number }\end{array}$ & Contents of sentences \\
\hline 1 & $\begin{array}{l}\text { 2017-12-14 12:47:50 } \\
\text { アドミッションポリシー | 国立大学法人 } \\
\text { 秋田大学一Google Chrome } \\
\text { Admission Policy | National University } \\
\text { Corporation Akita University－Google Chrome } \\
\text { https://www.akita-u.ac.jp/honbu/exam/ex_policy } \\
\text {.html }\end{array}$ \\
\hline 2 & $\begin{array}{l}\text { 2017-12-14 12:48:11 } \\
\text { 秋田大学/大学トップ| Benesse マナビジョ } \\
\text { ンーGoogle Chrome } \\
\text { Akita University/ Top Page | Benesse } \\
\text { Manavision－Google Chrome } \\
\text { https://manabi.benesse.ne.jp/daigaku/school/108 } \\
\text { 0/index.html }\end{array}$ \\
\hline 3 & $\begin{array}{l}\text { 2017-12-14 12:48:24 } \\
\text { センターの特色 | 国立大学法人 秋田大学 } \\
\text {-Google Chrome } \\
\text { Characteristics of the Center | National } \\
\text { University Corporation Akita University } \\
\text {-Google Chrome } \\
\text { https://www.akita-u.ac.jp/icremer/program.html }\end{array}$ \\
\hline
\end{tabular}


Table 3. Operation pattern items and their contents in comparative experiments.

\begin{tabular}{|c|c|c|}
\hline No. & Item & Contents \\
\hline I & $\begin{array}{l}\text { A copied } \\
\text { website } \\
\text { (3 types) }\end{array}$ & $\begin{array}{l}\text { - A website unrelated to the text } \\
\text { described in the document } \\
\text { - A website associated with the text of } \\
\text { the file, but not directly present in the } \\
\text { file } \\
\text { - A website associated with the text of } \\
\text { the file and also listed in the file }\end{array}$ \\
\hline II & $\begin{array}{c}\text { Place to } \\
\text { paste } \\
\text { (4 types) }\end{array}$ & $\begin{array}{l}\text { - Nothing written } \\
\text { - The front part of the sentence is } \\
\text { already written } \\
\text { - Between sentences that are already } \\
\text { written } \\
\text { - Behind part of a sentence that is } \\
\text { already written }\end{array}$ \\
\hline III & $\begin{array}{l}\text { About } \\
\text { Editing } \\
\text { (11 } \\
\text { types) }\end{array}$ & $\begin{array}{l}\text { - No editing } \\
\text { - Delete: } 3 \text { types }(20 \%, 50 \% \text {, and } 80 \% \\
\text { of the total) } \\
\text { - Add: } 4 \text { types }(20 \%, 50 \%, 80 \% \text {, and } \\
\text { 100\% of the total) } \\
\text { - Delete and add: } 3 \text { types } \\
\text { (Summarize, Increase the number of } \\
\text { periods without changing the meaning } \\
\text { of the sentence, Reduce the number of } \\
\text { periods without changing the meaning } \\
\text { of the sentence) }\end{array}$ \\
\hline
\end{tabular}

(b) Experimental results

The results obtained showed that the success rate was 124 out of the 132 patterns (approximately 94\%) using the proposed method and 30 out of the 132 patterns (approximately 23\%) using the comparison method. The reason for the small number of successes using the comparison method could be attributed to the fact that a considerable number of corresponding web pages are found. This is so because the comparison method sets frequent words in the document as keywords and performs each search. Thus, detecting reference information for keywords that appear infrequently is difficult. The detection rate and efficiency of sentences inserted are low because of the detection by keywords. As the proposed method detects based on the text that exists using the copy and paste operations, it is considered to be useful for detecting the text inserted and also advantageous for collection of information necessary for the reference.

\section{Test for Detection of Sentences Created without Copy Operation}

\subsection{Overview}

The proposed method described in Chapter 2 is effective for detecting sentences created using the copy and paste operations. However, this method is unable to detect sentences quoted without copy and paste operations. On the contrary, the timing at which the citation sentence is inserted by an operation other than the copy and paste operation can be detected and judged using other log information. Using the proposed method, in addition to acquiring the PC operation log, the location being referred to during work can also be determined by measuring the sight line and combining them. Therefore, this chapter examines how to detect sentences quoted without using the copy and paste operations. Next, we will examine the position of gaze and keyboard operations when a user reads sentences written on papers and enters it on a PC.

\subsection{Experimental Method}

Subjects of the experiment enter sentences written on papers to the working file on the PC using word processing for $30 \mathrm{~min}$. For the proposed method to work, while working, the logs of gaze point coordinates and keyboard operations will be acquired. There are four types of documents and the subject rests for $1 \mathrm{~min}$ each time one type of input is completed. The paper document is placed on the left side of the keyboard. So, when the user looks toward the left of the keyboard, it can be determined that the user is looking at the paper document. The gaze point coordinates are acquired every $10 \mathrm{~ms}$ and the keyboard operation log is acquired each time the up / down key is hit. In addition, we use a video camera to capture the work scene to use it to confirm the actual movement of the user. The experiment is conducted for 4 days.

For the experiment, the subjects are three graduate students (A to C) in their 20s who routinely use a PC. The equipment and software used are as follows:
$\checkmark \quad$ PC: Fujitsu ${ }^{\circledR}$ ESPRIMO D588 / TW ${ }^{(9)}$
$\checkmark$ OS: Microsoft ${ }^{\circledR}$ Windows $10^{\circledR}$
$\checkmark \quad$ CPU: Intel ${ }^{\circledR}$ Core $^{\mathrm{TM}}$ i7-8700 CPU @ 3.20GHz 3.19Hz
$\checkmark \quad$ Mouse: Fujitsu ${ }^{\circledR}$ MSB0939T
$\checkmark \quad$ Keyboard: Fujitsu ${ }^{\circledR}$ KB410 K USB JP
$\checkmark$ Display: DELL ${ }^{\circledR} 2007 \mathrm{FPb}^{(10)}$
$\checkmark \quad$ Camera: SONY ${ }^{\circledR}$ FDR AX60 $0^{(11)}$
$\checkmark \quad$ Software: Microsoft ${ }^{\circledR}$ Word $^{\circledR}$ 
$\checkmark \quad$ Eye Tracker: Tobii ${ }^{\circledR}$ Eye Tracker $4 C^{(12)}$

\subsection{Experimental Results}

The gaze point obtained is shown in Table 4. The numbers indicate the gaze point coordinates existing at each coordinate area ("PC screen," "Keyboard," and "Documents"). The number of gaze point coordinates other than these are indicated under "Other." As you can see in Table 4, in most of the cases, the focus is primarily on "Display" and the "Keyboard" is at the second place, but for the first and fourth day of the subject C, the "Keyboard" is more focused than the "Display." This can be viewed as the subject $\mathrm{C}$ is operated while watching at the "Keyboard". Also, it is seen that the "Documents" has a shorter time for focusing than the other two areas. Since "Other" includes the attention point during the transition from "Display" to "Keyboard," it has a value higher than "Documents."

We focus on the fourth day data with the largest number of acquired data among subjects A doing touch typing. Fig. 4 shows the movement of part of the gaze of the subject A on the fourth day and the time transition of the keyboard operation log. The typing speed during the work of Subject A was an average of 0.17 s. Also, the keyboard operation was continuously performed except during the break time. Therefore, keyboard operation logs in the graph are displayed as continuous values. From Fig. 4, it is understood that the keyboard operation is performed while alternately viewing the document and the screen of the PC. In addition, it can be determined that the keyboard operation has been performed with reference to a place other than the software in which the sentence has been inserted. Thus, by a combined analysis of the presence / absence of the keyboard operation and the movement of the gaze point, it is possible to find out the place that the user referred during the sentence input operation. Therefore, in addition to the acquisition of the keyboard operation log, it is suggested that the gaze measurement also acquires information other than the $\mathrm{PC}$ as a reference.

\section{Conclusions}

In this paper, we examined the improvement of the conventional method and the case of reading a document and generating a sentence without using the copy and paste operation. As a result, the proposed method was found to be useful in detecting the inserted text and is advantageous for collecting information necessary for citing references. By performing gaze measurement, in addition to keyboard

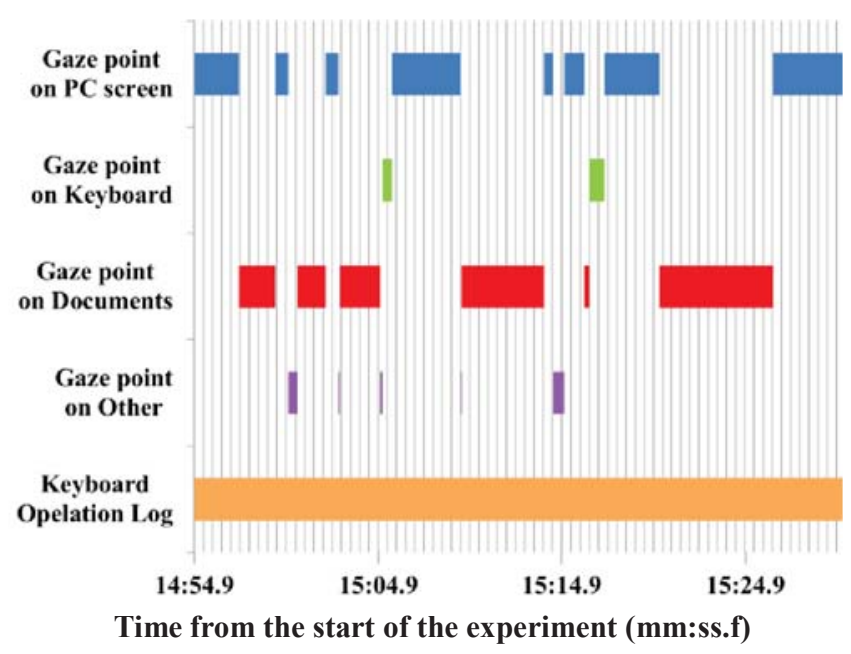

Fig. 4. The movement of part of the gaze of the subject A on the fourth day and the time transition of the keyboard operation $\log$.

Table 4. Percentage of viewpoint data obtained.

\begin{tabular}{|c|c|r|r|r|r|r|}
\hline Subject & Day & PC screen & Keyboard & Documents & Other & Total \\
\hline \multirow{4}{*}{ A } & 1 & 30,664 & 2,469 & 119 & 1,837 & 35,089 \\
\cline { 2 - 7 } & 2 & 19,168 & 3,319 & 1,118 & 6,124 & 29,729 \\
\cline { 2 - 8 } & 3 & 57,106 & 4,728 & 1,029 & 2,657 & 65,520 \\
\cline { 2 - 8 } & 4 & 60,522 & 3,637 & 1,402 & 2,825 & 68,386 \\
\hline \multirow{4}{*}{ B } & 1 & 11,060 & 788 & 464 & 4,428 & 16,740 \\
\cline { 2 - 8 } & 2 & 19,209 & 4,651 & 1,775 & 4,588 & 30,223 \\
\cline { 2 - 7 } & 3 & 23,281 & 116 & 152 & 911 & 24,460 \\
\cline { 2 - 7 } & 4 & 4,679 & 77 & 83 & 655 & 5,494 \\
\hline \multirow{4}{*}{ C } & 1 & 43,705 & 80,469 & 2,837 & 13,826 & 14,0837 \\
\cline { 2 - 7 } & 2 & 31,214 & 26,381 & 1,500 & 10,846 & 69,941 \\
\cline { 2 - 7 } & 3 & 32,220 & 3,170 & 2,326 & 14,172 & 51,888 \\
\cline { 2 - 7 } & 4 & 49,766 & 63,455 & 2,553 & 9,391 & 125,165 \\
\hline
\end{tabular}

operation log acquisition, it was also demonstrated that information other than PC may be acquired as a reference.

In the future, we plan to analyze and examine other subjects. In addition, we will perform gaze measurement and operation log acquisition in various situations, such as when the sentence copied from other file and copy and paste operations are included.

In addition, it is considered that the gaze point and the operation log change when the age, affiliation, and skills are different. Therefore, we plan to acquire gaze measurement and operation logs for various subjects.

\section{Acknowledgment}

This research was supported by JSPS KAKENHI, Grant Number JP18K02852. 


\section{References}

(1) Takaaki Matsuzawa : "Research misconduct in Japan: Macro-analysis based on open information (1)" Journal of Information Processing and Management, Vol. 56, No. 3, pp.156-165, 2013

(2) Takaaki Matsuzawa : "Research misconduct in Japan: Macro-analysis based on open information (2)" Journal of Information Processing and Management, Vol. 56, No. 4, pp. 222-235, 2013

(3) "Copypelna", "ANK Co., Ltd", http://www.ank.co.jp/works/products/copypelna/ (Accessed 24 May, 2019)

(4) Chikako Ishizawa, Masahiro Toshima, Yoichi Kageyama, and Makoto Nishida : "Detection Method to Prevent Reference Omissions Using Logs of Text Inserted by Copy-and-Paste Operations", International Journal of the Society of Materials Engineering for Resources, Vol. 23, No. 1, pp. 98-104, 2018

(5) "NMeCab - .NET Morphological analyser", https:/jja.osdn.net/projects/nmecab/ (Accessed 24 May, 2019)

(6) "MeCab: Yet Another Part-of-Speech and Morphological Analyzer", http://taku910.github.io/mecab/ (Accessed 24 May, 2019)

(7) "mecab-ipadic-NEologd: Neologism dictionary for MeCab,", https://github.com/neologd/mecab-ipadic-neologd (Accessed 24 May, 2019)

(8) "SlothLib", http://www.dl.kuis.kyoto-u.ac.jp/slothlib/ (Accessed 24 May, 2019)

(9) "Direct Series ESPRIMO D588 / VW Details: FUJITSU PC", "Fujitsu WEB MART" http://www.fujitsu-webmart.com/pc/webmart/ui6300.js p (Accessed 24 May, 2019)

(10) "Dell 2007FP Support | Manuals and Documents", "Dell Japan", https://www.dell.com/support/home/jp/ja/jpbsd1/product -support/product/dell-2007fp/manuals

(Accessed 24 May, 2019)

(11)"FDR-AX60 | Mouser Digital Camcorder Handycam", "SONY", https://www.sony.jp/handycam/products/FDR-AX60/ (Accessed 24 May, 2019)

(12) "Eye Tracker 4C for PC Gaming", "Tobii Gaming", https://gaming.tobii.com/product/tobii-eye-tracker-4c/ (Accessed 24 May, 2019) 